plications assumed to be absent, so that attention can be focused on the interplay of what are supposed to be the most important influences. The models obey exact mathematical laws and the art of building them requires some mathematical expertise. Many economists know enough of one branch of mathematics to build some imposing models : few know enough to understand the models built by the others. Prof. R. G. D. Allen's book should help to spread the mutual understanding.

Mathematical economics or model-building is, however, still mainly the subject either of specialist periodicals devoted to it as to a hobby such as chess, or, more usefully, of appendixes and footnotes in more serious works which really are about economics. It here serves to clear up knotty logical points, cropping up in the course of discussing practical questions, in terms of political arithmetic and history. Unless he remembers this subsidiary part played by mathematical economics in economics proper, any reader coming fresh to this book from a study of mathematics or science will be in danger of forming a very distorted impression of what economics is about.

This book confines itself to a limited but representative selection of types of economic model, each of which has been created in response to the genuine needs and interests of bona fide economists. The author shows how the same few basic mathematical techniques appear over and over again in widely different fields of application: and he provides a series of lucid mathematical chapters, giving the basic training in these selected mathematical techniques. Their level is sufficiently advanced for it to be doubtful whether, apart from Prof. Allen himself, any reputable English economist could claim that he had already mastered much more than half of them. The mathematical chapters in this book are written in a style very well suited to the requirements of those who would care to master more.

By denying himself any treatment of questions relating to probability or random variates, the author allows himself a fuller treatment of other topies. $\mathrm{He}$ gives considerable emphasis to the application of linear differential equations and difference equations to the study of models reproducing trade-cycle phenomena. Such methods are useful only to models yielding oscillatory movements in the variables concerned: they are usually inadequate to analyse models which yield two alternating positions of temporary stable equilibrium, boom and slump: accordingly such non-linear models are given only very brief mention : yet it may be that they are of more relevance to the world we live in. This suggests one unavoidable handicap imposed by the method of selection of subject-matter according to its mathematical content: namely, that the more mathematically awkward subjects tend to be omitted.

Linear programming and von Neumann's theory of two-person games receive liberal attention : these are of relevance in situations where one knows exactly what one wants and how much, and the extent of the resources that are available for obtaining it. This is the branch of economics devoted to war and siege, but it also has applications to the operations of the very large business unit and of planning committers. The calculation of optimum programmes is in practice very tedious, but the increasing availability of electronic calculators will reduce the importance of this consideration.
Vector and matrix algebra also receive full treatment. These, for example, enable the economist to extend his arguments from the representative man consuming the consumption-good produced by industry, to deal with families of varying composition and income consuming a series of consumption-goods and services provided by a list of industries and caterers.

This book should be compulsory reading for all economists seeking to publish articles involving economic models. $\quad$ D. G. ChAMPERNowne

\section{PACIFIC OCEANOGRAPHY}

\section{Oceanic Observations of the Pacific, 1949}

Edited by N. W. Rakestraw, Paul L. Horrer and Warren S. Wooster. Pp. 363. (Berkeley and Los Angeles : University of California Press ; London : Cambridge University Press, 1957.) 34s, net.

$T$ HE usefulness of oceanographical data is increased by early publication, but getting them prepared for publication is not easy. The purpose of the observations is often exciting and rewarding, and everyone gets on with it, and probably uses only a selection of the data. The task of checking thermometer corrections, salinity figures, density calculations, and other computations for all the data, for other uses and for others to use, is an urgent duty which is often neglected owing to the claims of direct interpretation and the need of making more observations; there are also the costs of publication and distribution.

The Scripps Institution of Oceanography of the University of California has done marine science a good service by making provision for regular publication of physical and chemical data from the Pacific Ocean. The first volume collects observations made by the Scripps Institution, the Department of Oceanography of the University of Washington, the U.S. Navy Electronics Laboratory and the Pacific Oceanic Fishery Investigations of the U.S. Fish and Wildlife Service, and offers to publish the data of other agencies which work in the Pacific Ocean. It is a handsome well-bound photoprinted book. The first of a series, it contains observations made in 1949 hitherto unpublished, together with charts showing when they were made and a list of published papers referring to the 1949 cruises and to results already obtained from them. The observations cover the ocean north of the equator as far west as Hawaii, and there are closely spaced, repeated, measurements extending four hundred miles off shore between $46^{\circ}$ and $25^{\circ} \mathrm{N}$. There are not many observations from depths greater than $1,200 \mathrm{~m}$. The remainder of the ocean, and some of the Indian Ocean, and covered by bathythermograph observations, and there are so many thousands that it is not practical to publish them either as photographs or in lists. The numbers available in each 5 -degree square are shown in the charts, and copies of the slides are deposited at the Scripps Institution.

Subsequent volumes containing observations made in each succeeding year will be published as soon as they are ready, and there will also be one for obser vations made prior to 1949 together with a bibliography of earlier sources.

The editorial board at the Scripps Institution, its consultants in the agencies participating in the scheme, and the publishers are to be congratulated on a fine achievement.
G. E. R. Deacon 